\title{
The Effect of Leadership Style on Employee Engagement: The Moderating Role of Task Structure
}

\author{
Rui Zhao, Yuhua Sheng \\ Business School, Nanjing Normal University, Nanjing, China \\ Email: 2546465926@qq.com
}

How to cite this paper: Zhao, R. and Sheng, Y.H. (2019) The Effect of Leadership Style on Employee Engagement: The Moderating Role of Task Structure. Open Journal of Social Sciences, 7, 404-420. https://doi.org/10.4236/jss.2019.77033

Received: June 27, 2019

Accepted: July 27, 2019

Published: July 30, 2019

Copyright (อ 2019 by author(s) and Scientific Research Publishing Inc. This work is licensed under the Creative Commons Attribution International License (CC BY 4.0).

http://creativecommons.org/licenses/by/4.0/

\section{(c) (i) Open Access}

\begin{abstract}
According to the social exchange theory, based on the 335 valid questionnaire data, the article uses the hierarchical regression method to examine the influence of authoritarian leadership and charismatic leadership on employee engagement and the moderating effect of task structure. The results show that charismatic leadership is significantly positively correlated with employee engagement, and there is a significant positive correlation between vigor, dedication and absorption. Authoritarian leadership is significantly negatively correlated with employee engagement, and is significantly negatively correlated with vigor and dedication. The task structure plays a moderating role between authoritarian leadership and employee engagement. Studies have shown that combined with contextual factors can better explain the role of leadership quality in leadership effectiveness, and also provide guidance and suggestions for leadership selection and practice, that is, in the context of high-task structure, organizations should prioritize the selection of individuals with authoritarian orientation as leaders.
\end{abstract}

\section{Keywords}

Charismatic Leadership, Authoritarian Leadership, Task Structure, Employee Engagement

\section{Introduction}

The competition among enterprises largely depends on the degree of employee engagement. How to mobilize the enthusiasm of employees and improve the degree of employee engagement is not only a theoretical topic that has been discussed and studied by academic circles, but also a practical problem faced by 
business managers. A large number of empirical studies have consistently found that higher work involvement has a positive impact on individual work [1], which is positively correlated with employees' job performance, organizational citizenship behavior and job satisfaction. Harter, Schmidt and Hayes found that employee engagement is significantly positively correlated with organizational performance [2]. Therefore, how to make employees increase their engagement, that is, to find the antecedent variables affecting engagement, has become the research focus. Leadership is an important situational variable in the employee's work situation, which will have a significant impact on the employee's psychology, attitudes and behavior. There are two main styles of leadership in Chinese companies. One is the authoritarian leadership style that emphasizes the personal authority and control of the leader. The other is the charismatic leadership style that influences the subordinates' attitude and behavior by describing inspiring vision and actively meeting their needs [3]. The academic circle has not conducted a comparative study on charismatic leadership and authoritarian leadership, and it will be more valuable to bring the charismatic leadership with freedom and equality and the authoritarian leadership style with China's unique characteristics into the same framework for a comparative study.

As the most representative core dimension of the paternalistic leadership ternary model, authoritarian leadership can be studied as an independent leadership style [4]. Since Farh and Cheng established the paternalistic leadership ternary model [5], scholars have carried out a lot of empirical research, but the relevant research findings are different: between the authoritarian leadership and the subordinates' attitudes, behaviors and other outcome variables. Inconsistencies were found in the relationship. For example, Zheng Boxun analyzed the data of 240 pairs of leaders in the mainland enterprise organizations, and found evidence that authoritarian leaders improved employee loyalty and improved organizational commitment. The results also showed their leadership satisfaction with employees. Job satisfaction has not been significantly affected [6], while other scholars have obtained conflicting research conclusions. Zhang Xinan, $\mathrm{He}$ Hui, Gu Feng found that the authoritarian behavior of team leaders has no significant impact on team performance [7]. So, what is the impact of authoritarian leadership on employee engagement? The academic circles have not yet studied it; in many respects, charismatic leadership has been shown to have a positive impact on organizations and individuals, and can charismatic leadership have a positive impact on employee engagement? So, the first two questions that this study wants to explore are the relationship between charismatic leadership, authoritarian leadership, and employee engagement. Is there a difference in the role of charismatic leadership style and authoritarian leadership style in employee engagement?

According to leadership contingency theory, there is no universally applicable leadership style [8], and the effectiveness of leadership style is inevitably affected by organizational contextual factors. Therefore, according to the theory of leadership change, it is necessary to match the leader's behavior with the situation 
in order to achieve leadership effectiveness. Researchers have noticed that different leadership styles have different strengths and weaknesses, and different leadership styles need to match different contexts. In one situation, one leader can be a successful leader, while in another context it cannot be [9]. Therefore, this study will conduct a contingency analysis of charismatic leadership and authoritarian leadership.

In summary, this study introduces the task structure, the contextual variable, and the third question to be explored: Does the task structure affect the relationship between charismatic leadership, authoritarian leadership, and subordinates' engagement. That is, from the perspective of contingency management, when the level of task structuring is at what level, the organization should adopt which leadership style is appropriate, and thus improve the effectiveness of leadership, which is essential to improve the competitive advantage of the enterprise.

Task structure has an important impact on the effectiveness of leadership behavior, which is a key situational factor affecting the effectiveness of leadership in any organization. It will inevitably affect the relationship between the leader's behavior and the behavior of the corresponding subordinates. This research to enterprise staff as the research object, on the basis of leadership contingency theory, social exchange theory, the charismatic leadership, authoritarian leadership to subordinate a comparative study on the influence of the engagement, reveals the similarities and differences between these two kinds of style of leadership role, then add the task structure the situational variables, explore the task structure of relations between the two types of leadership and subordinate behavior, the influence of rich leadership contingency theory on the one hand, on the other hand, can provide the basis for leadership selection in organization.

\section{Literature Review}

\subsection{Charismatic Leadership and Employee Engagement}

Scholars have different views on the connotation of charismatic leadership [10]. House believes that the term "charisma" should be understood from the perspective of the influence of leaders on followers or the relationship between leaders and subordinates. Charismatic leaders are summarized into five dimensions, including role simulation, image building, goal clarification, expression of high expectation and confidence, and motivational behavior [11]. Bass thinks, charismatic leaders can inspire followers, followers worship, identity, inspire followers to achieve the desired goal, and will be the charismatic leadership behavior as good impression management, and values associated with work, depicting attractive vision, role model, expressive behavior and eloquent [12] 6 kinds of behavior. However, the five-factor model proposed by Conger-Kanungo et al. is more typical and has been adopted and verified by a large number of empirical studies. This model will also be used in this study. The specific dimension are as follows: 1) strategic vision and expression; 2) personal risk taking; 3) highly sen- 
sitive to the environment; 4) sensitivity to subordinates' needs; 5) displaying unconventional behaviors [13].

Nowadays, Schaufeli, Salanova, Gonzalez-Roma, \& Bakker's definition of engagement have been widely adopted by scholars. Schaufeli et al. believed that engagement is a positive and complete working state related to work, which can be summarized into three dimensions of vigor, dedication and absorption [14]. At present, there are different opinions on the connotation of engagement in academic circles, but they all agree that engagement is the combination of work energy, work willingness and integration [15].

Charismatic leaders' vision of motivation and care for their members can greatly infect employees and fully stimulate their engagement. First of all, charismatic leaders are good at observing the opportunities in change, establishing an attractive organizational vision, and building the hope and confidence of subordinates for the future, so as to enhance the motivation of employees [16]. This is very similar to transformational leadership. Chen Yongxia, Jia Liangding, Li Chaoping, Song Jiwen, Zhang Junjun found that transformational leadership was significantly positively correlated with organizational commitment and extra effort of employees [17]. At the same time, when employees perceive that their leaders are attractive, they will identify with values and show great enthusiasm for the requirements of leaders, so they are more willing to work. Secondly, charismatic leaders have high expectations and confidence in their subordinates. According to the social exchange theory, employees feel recognized by their leaders, so that they can feel their own value and motivate their subordinates to work hard to achieve challenging goals. Finally, charismatic leaders are good at combining the vision of the organization with the needs of subordinates, so as to motivate employees to have a strong sense of identity and responsibility for achieving organizational goals [18], so that employees can fully experience the intrinsic value of work and voluntarily increase their engagement. Finally, charismatic leaders often express their concern for the needs of their subordinates. According to the social exchange theory, when leaders are sensitive to and respond to changes in employees' needs, employees will work more actively to repay their leaders. As a result, subordinates who are cared about by charismatic leaders are more likely to increase their engagement.

Therefore, based on the above analysis, the following assumptions are made:

H1: Charismatic leadership has a significant positive predictive effect on employee engagement.

H1 a: Charismatic leadership is positively related to employee vigor.

$H 1$ b: Charismatic leadership is positively related to employee dedication.

H1c. Charismatic leadership is positively related to employee absorption.

\subsection{Authoritarian Leadership and Employee Engagement}

The connotation of authoritarian leadership is extremely rich, which is consistent with the traditional Chinese culture's emphasis on "superior being superior and inferior being inferior", highlighting the huge power distance between supe- 
rior and subordinate in Chinese organizations [19]. Authoritarian leaders emphasize that their authority is absolute and cannot be challenged. They strictly control their subordinates and require them to obey [20], which is embodied in four behaviors. Belittling subordinates' abilities means ignoring their Suggestions and contributions. Image decoration means that the leader manipulates information to maintain power distance and maintain his dignity. Didactic behavior refers to that the leader has strict requirements on the performance of subordinates, and will give reprimands and direct guidance to underperforming subordinates [21].

Many empirical studies have found that the response of employees in the organization is significantly negatively correlated with the authoritarian leadership style. For example, zheng Boxun, Zhou Lifang and Fan Jingli found in their studies that authoritarian leadership can significantly weaken employees' trust in leaders, job satisfaction and employee loyalty. Zhang Yan and Huai Mingyun found that organizational citizenship behavior of employees would be significantly reduced due to authoritarian leadership style [22]. Fu Xiao and Li Yi found that authoritarian leadership would seriously affect the innovation ability and work performance of employees [23]. Li Rui and Tian Xiaoming showed a significant negative correlation between authoritarian leadership and subordinates' forward-looking behavior [24].

This study argues that authoritarian leadership has a negative impact on employee engagement. First of all, authoritarian leaders have obvious dictatorial style, high concentration of power, unwilling to empower employees, and require employees to obey unconditionally. This, to a certain extent, obeys and succumbs to authoritarian leaders, but the psychological pressure brought by authoritarian leadership and insecurity can cause employees to resist the leadership authority from the heart [25], resulting in employees with rebellious psychology and resistance, thus reducing their engagement; Second, authoritarian leaders often devalue the subordinates, deliberately ignore or criticize the contribution of subordinates, and even use themselves The status of the subordinates [26], in this case, the social needs of employees are not satisfied, they will not be active and not take the initiative as the safest way to deal with, the negative treatment of leadership assignment tasks, authoritarian leadership to employees negative evaluation can also hurt employees' self-confidence. Employees passively believe that they are not suitable for their work. Such self-doubt will make employees tend to escape and are not willing to actively participate in work. At the same time, authoritarian behavior of authoritarian leadership is too concerned. Employee performance, does not want employees to interfere too much in management work other than their own performance, thus It reduces the enthusiasm and responsibility of employees to solve problems proactively. Finally, authoritarian leaders maintain distance between their subordinates through image decoration, lack of personal emotional communication, do not depict an inspiring vision for future development, and do not convey a sense of 
mission to their subordinates. The relationship between leaders and subordinates is only a short-term exchange relationship based on interests. Driven by the principle of reciprocity in social exchange theory, employees will only complete their own work, and will not be willing to increase their investment level and reduce their engagement.

Therefore, based on the above analysis, the following hypotheses are proposed:

H2: Authoritarian leadership has a significant negative predictive effect on employee engagement.

H2 a: Authoritarian leadership is negatively correlated with employee vigor.

$H 2 b$ : There is a negative correlation between authoritarian leadership and employee dedication.

H2c. There is a negative correlation between authoritarian leadership and employee absorption.

\subsection{Comparison of the Influence of Authoritarian and Charismatic Leaders on Employee Engagement}

With the development of The Times, employees, especially those born in the 1990s, are not focusing on salary and salary at first, but on meeting their personal needs. According to Maslow's hierarchy of needs theory, charismatic leaders' vision stimulation and care for members can greatly meet subordinates' needs for respect and self-realization, make subordinates willing to believe and obey the leader, and make efforts to realize the vision proposed by the leader, and voluntarily increase their engagement in work. However, authoritarian leaders emphasize that the authority of leaders should not be challenged, and rely on the deterrence of their position power to make subordinates obey and obey. Although this makes subordinates obey and submit to the leadership to a certain extent, in the long run, the psychological pressure and insecurity brought by authoritarian leadership will lead subordinates to resist the leadership authority, thus leading to their reduced engagement.

Therefore, based on the above analysis, the following hypotheses are proposed:

H3: charismatic leadership predicts engagement better than authoritarian leadership.

\subsection{Task Structure as a Moderator}

According to the leadership contingency theory, there is no universally applicable leadership style, and the effectiveness of leadership style is inevitably affected by organizational context factors [27], including charismatic leadership and authoritarian leadership. In 1951, Fiedler, a pioneer of contingency management, proposed the concept of organizational task structure and discussed its impact on leadership effectiveness. Fiedler defined the task structure as the purpose of the task, the method to complete the task and the clarity of the task performance assessment criteria. An organization with a high degree of task structure has a 
clear work goal, which can decompose tasks into standard procedures and steps, and can objectively and accurately assess work performance. Organizations with low task structure lack clear objectives, clear procedures and procedures, and objective and accurate performance evaluation methods.

When the subordinate's tasks contain many conceptual components or complete tasks without specific and certain methods, that is, when the task structure is low, then the charismatic leader is like a beacon, which can fully exert its own advantages and express the vision as an organization or team. Set a viable goal and be good at solving problems caused by environmental uncertainty. Charismatic leaders can make up for the shortcomings of low-task structure scenarios. Therefore, in the case of a low task structure, a charismatic leader can promote the subordinate's engagement. In the case of high mission structure, the mission objectives are relatively clear, the organizational system is gradually improved, and the advantages of charismatic leaders are no longer obvious. At this point, what the organization needs is a way for the leader to find a way to achieve it, rather than finding a new one. At this time, if charismatic leadership is adopted, the requirements of the leaders and the requirements of the organization are contradictory to the employees. The organization requires them to complete the work according to the established procedures. The requirements of the charismatic leaders are to set new goals and break through themselves. As the employees are very contradictory and their work goals are confusing, then the employees have no certain direction of efforts, and they do not know which direction to work in, and the degree of engagement will be reduced. Since China is a country with a high power distance, its subordinates are afraid of losing their own resources and will be afraid of the authority of the leaders. Therefore, they will voluntarily increase their investment and increase their engagement. Therefore, in the case of a high task structure, the use of authoritarian leadership is more effective and can increase employee engagement.

Based on the above analysis, the following assumptions are made:

H4: The task structure moderates the relationship between authoritarian leadership and employee engagement.

H5: The task structure moderates the relationship between charismatic leadership and employee engagement.

Therefore, according to the above, the theoretical model of this study is proposed, as shown in Figure 1. From the perspective of employees themselves, the relationship between charismatic leadership, authoritarian leadership and employee engagement and the moderating effect of task structure were studied.

\section{Research Methods}

\subsection{Data Collection}

Data were collected through questionnaire survey in this study, and samples were obtained in two ways: 1) online questionnaire was released through the questionnaire star platform; 2) send electronic or paper questionnaires to em- 
ployees of relevant enterprises through key contacts. The subjects of this study were from Henan, Anhui, Jiangsu, Hebei, Beijing and other places. A total of 400 questionnaires were issued. 365 questionnaires were actually recovered, with a recovery rate of $91.25 \%$. Table 1 reflects the demographic characteristics of the data which we used in this paper.

\subsection{Measurement}

The selection of the measurement indicators influences the reliability and validity of the final survey data. Therefore, we drew on the maturity scales of relevant variables abroad and made necessary revisions. As a result, these items were designed in the form of 7-point Likert scales, and respondents are required to rate the Chinese items, rating from $1=$ strongly disagree to $7=$ strongly agree.

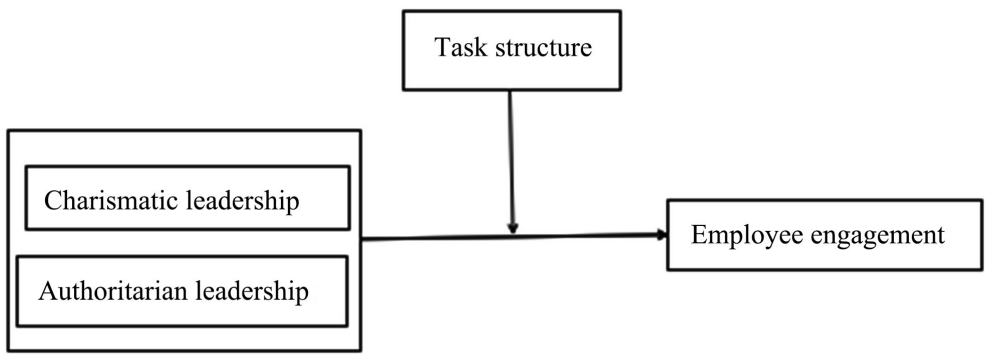

Figure 1. Theoretical model.

Table 1. Demographic characteristics of the analytic sample.

\begin{tabular}{|c|c|c|c|}
\hline \multicolumn{2}{|c|}{ Demographic characteristics } & \multirow{2}{*}{$\begin{array}{c}\text { Unweighted n's } \\
176\end{array}$} & \multirow{2}{*}{$\begin{array}{c}\text { Weighted Percentage } \\
52.5 \%\end{array}$} \\
\hline & Male & & \\
\hline Сениет & Female & 159 & $47.5 \%$ \\
\hline \multirow{4}{*}{ Age } & $\leq 25$ & 142 & $42.4 \%$ \\
\hline & $26-40$ & 100 & $29.9 \%$ \\
\hline & $41-55$ & 89 & $26.6 \%$ \\
\hline & $>56$ & 4 & $1.1 \%$ \\
\hline \multirow{3}{*}{ Education } & Junior college or below & 97 & $29.0 \%$ \\
\hline & Bachelor's degree & 159 & $47.5 \%$ \\
\hline & Master's degree or above & 79 & $23.5 \%$ \\
\hline \multirow{5}{*}{ Working Time } & $\leq 1$ & 140 & $41.8 \%$ \\
\hline & $2-3$ & 97 & $29.0 \%$ \\
\hline & $4-5$ & 27 & $8.0 \%$ \\
\hline & $6-10$ & 32 & $9.6 \%$ \\
\hline & $\geq 10$ & 39 & $11.6 \%$ \\
\hline \multirow{4}{*}{ Working Years } & $\leq 5$ & 211 & $63.0 \%$ \\
\hline & $6-10$ & 53 & $15.8 \%$ \\
\hline & $11-20$ & 24 & $7.2 \%$ \\
\hline & $\geq 20$ & 47 & $14.0 \%$ \\
\hline
\end{tabular}


Charismatic leadership: the $\mathrm{C}-\mathrm{K}$ scale developed by Conger and Kanungo (2000) has been widely used in relevant empirical studies because it has shown sufficient reliability and validity in previous studies. In addition, C-K scale of charismatic leadership perceived behavior composition is relatively stable, so this research adopts the $\mathrm{C}-\mathrm{K}$ scale, the scale including strategic vision, sensitivity to the environment, on the sensitivity of the employee needs, personal adventures and unconventional behavior five dimensions, a total of 20 items, such as "plan with vision, often organization puts forward the idea of future work", etc. In this study, Cronbach's $\alpha$ of the scale reached 0.97.

Authoritarian leadership: the sub-scale of authoritarian leadership developed by Zheng Boxun, Zhou Lifang and Fan Jingli (2000) in the context of Chinese culture is adopted. This scale has been widely used in previous studies and has good reliability and validity. The scale is divided into four dimensions: authoritarian behavior, derogatory ability of subordinates, image decoration, and educational behavior, with a total of 13 items, such as "he asked me to obey his leadership absolutely". In this study, Cronbach's $\alpha$ of the scale reached 0.94 .

Task structure: the task structure scale prepared by Tsui (1999) is adopted, with a total of 7 items, such as "the definition of group goals and tasks is fully clear and clear", "step-by-step process or standard process indicates the working steps and requires strict implementation" and so on. In this study, Cronbach's $\alpha$ of the scale reached 0.95 .

Employee Engagement: Schaufeli, W.B., Bakker, a. B., \& Salanova, m. (2006) [28] prepared a short version of uwes- 9 , which is a three-dimensional model applicable to different cultural backgrounds. It includes three dimensions: vigor, dedication, and absorption. In this study, Cronbach's $\alpha$ of the scale was 0.95 in total, 0.85 in vigor, 0.90 in dedication and 0.90 in absorption in each dimension.

According to relevant studies, five demographic variables including gender, age, time spent working with immediate supervisors, education level and length of service were selected as control variables in this study.

\subsection{Analysis Method}

Statistical analysis was performed using SPSS 22.0 and AMOS 23.0 software. Specific statistical analysis included: reliability analysis, confirmatory factor analysis, correlation analysis, and comparison of charismatic leaders and authoritarian leaders in predicting employee engagement. The hierarchical regression analysis and the multi-level regression analysis are used to test the role of the task structure in moderating the relationship between authoritarian, charismatic leadership and subordinates.

\section{Results}

\subsection{Confirmatory Factor Analysis}

The confirmatory factor analysis was carried out using AMOS 23.0 software to determine the discriminant validity among the variables in the model, and the results were shown in Table 2. According to the suggested criteria proposed by 
Bentler (1990), $x 2 / \mathrm{df} \leq 3.0, \mathrm{CFI} \geq 0.90$, TLI $\geq 0.90$, IFI $\geq 0.90$, and RMSEA $\geq$ 0.05 indicate that the single-factor, two-factor, and three-factor model fitting is not acceptable, and the four-factor model fitting degree is good, indicating that the variables have good discriminant validity.

\subsection{Descriptive Statistics}

The mean value, standard deviation and correlation coefficient of each variable are shown in Table 3. As can be seen from Table 3, charismatic leadership is significantly positively correlated with engagement $(\beta=0.70, \mathrm{p}<0.01)$, and $\mathrm{H} 1$ is preliminarily supported. There was a significant negative correlation between authoritarian leadership and engagement $(\beta=-0.12, \mathrm{p}<0.05)$, and $\mathrm{H} 2$ was initially supported. Task structure was positively correlated with charismatic leadership $(\beta=0.14, \mathrm{p}<0.01)$, authoritarian leadership $(\beta=0.46, \mathrm{p}<0.01)$, and engagement $(\beta=0.14, \mathrm{p}<0.05)$. In addition, gender was significantly negatively correlated with engagement $(\beta=-0.15, \mathrm{p}<0.01)$, indicating that male was more engaged than female. There was a significant positive correlation between age and engagement $(\beta=0.12, \mathrm{p}<0.05)$, indicating that the older the employee, the higher the engagement.

The results of factor analysis showed that the four models had the best degree of fit, indicating that the variables had good discriminant validity and prepared for the following correlation analysis. Descriptive statistical analysis shows that charismatic leadership has a positive impact on employee engagement, and authoritarian leadership has a negative impact on employee engagement, initially validating the proposed hypothesis.

Table 2. Confirmatory factor analysis.

\begin{tabular}{cccccc}
\hline Model & Factor & $\chi^{2} / \mathrm{df}$ & RMSEA & IFI & CFI \\
\hline Four-factor model & CL, AL, TS, E & 1.42 & 0.04 & 0.98 & 0.98 \\
Three-factormodel & TS, CL + AL, E & 3.00 & 0.08 & 0.86 & 0.86 \\
Two-factor model & CL + AL + TS, E & 3.57 & 0.09 & 0.82 & 0.82 \\
Single factor model & CL + AL + TS + E & 4.04 & 0.10 & 0.78 & 0.78
\end{tabular}

Notes: $\mathrm{CL}=$ charismatic leadership, $\mathrm{AL}=$ authoritarian leadership, $\mathrm{TS}=$ task structure, $\mathrm{E}=$ engagement, the same below.

Table 3. Mean, standard deviations, and correlations among study variables.

\begin{tabular}{|c|c|c|c|c|c|c|c|c|c|}
\hline & 1 & 2 & 3 & 4 & 5 & 6 & 7 & 8 & 9 \\
\hline 1) Gender & 1 & & & & & & & & \\
\hline 2) Age & $-0.11^{\star}$ & 1 & & & & & & & \\
\hline 4) Working Time & 0.05 & $0.67^{\star \star}$ & $0.12^{*}$ & 1 & & & & & \\
\hline 5) Working Years & 0.03 & $0.69^{\star *}$ & $0.14^{*}$ & $0.71^{\star}$ & 1 & & & & \\
\hline 6) $\mathrm{CL}$ & 0.00 & -0.04 & 0.00 & 0.06 & 0.00 & 1 & & & \\
\hline 7) $\mathrm{AL}$ & -0.10 & 0.07 & -0.01 & 0.01 & 0.06 & -0.08 & 1 & & \\
\hline 8) Task Structure & -0.04 & $0.13^{\star}$ & 0.00 & 0.06 & 0.07 & $0.14^{* *}$ & $0.46^{\star *}$ & 1 & \\
\hline 9) Engagement & $-0.15^{\star \star}$ & $0.12^{\star}$ & 0.07 & 0.10 & 0.09 & $0.70^{\star *}$ & $-0.12^{\star}$ & $0.14^{*}$ & 1 \\
\hline Mean & 1.47 & 1.87 & 1.95 & 2.20 & 1.72 & 4.63 & 4.16 & 4.60 & 4.67 \\
\hline SD & 0.50 & 0.85 & 0.72 & 1.38 & 1.09 & 1.28 & 1.29 & 1.36 & 1.40 \\
\hline
\end{tabular}

Notes: $\mathrm{N}=335,{ }^{* *} \mathrm{P}<0.001 ;{ }^{* *} \mathrm{P}<0.01 ;{ }^{*} \mathrm{P}<0.05$. 


\section{Hypothesis Testing}

\subsection{Regression Analysis}

Vigor, dedication, absorption on three dimensions as the dependent variable and control variables (age, gender, education level, working years and working time), the independent variable (authoritarian leadership and charismatic leadership) into the regression equation, the test of an authoritarian, charismatic leadership and engagement in the three dimensions (vigor, dedication, absorption), the relationship between the results as shown in Table 4. As can be seen from Table 4, charismatic leadership is significantly positively correlated with vigor $(\beta=0.78$, $\mathrm{p}<0.001)$, dedication $(\beta=0.73, \mathrm{p}<0.001)$, and absorption $(\beta=0.80, \mathrm{p}<0.001)$, that is, H1a, H1b, and H1c are verified. Authoritarian leadership was significantly negatively correlated with vigor $(\beta=-0.11, \mathrm{p}<0.05)$ and dedication $(\beta=$ $-0.11, \mathrm{p}<0.05)$, but not significantly correlated with absorption, that is, H2a and $\mathrm{H} 2 \mathrm{~b}$ were verified, while $\mathrm{H} 2 \mathrm{c}$ was not.

\subsection{Comparative Analysis}

Table 5 shows the results of the hierarchical regression analysis of the dimensions of engagement between charismatic leadership and authoritarian leadership. From the results of the first half of Table 5, that is, the regression analysis of the first level, it can be seen that the predictive effect of the charismatic leadership on the dimensions of engagement has reached a significant level. After excluding the influence of the control variables, the increased $\Delta R^{2}$ values are respectively vigor 0.49 , dedication 0.41 , absorption on 0.41 . From the results of the lower part of Table 5, that is, the second level of regression analysis, in terms of authoritarian leadership, the predictive effect of the individual's vigor and dedication dimension has reached a significant level. However, the prediction effect on the absorption dimension is not significant. After excluding the influence of the control variables, the $\Delta \mathrm{R}^{2}$ values are 0.02 for vigor and 0.02 for dedication. From the above analysis, it can be seen that the charismatic leadership has a predictive effect on the vigor, dedication, and absorption dimensions of employee

Table 4. Regression results of authoritarian and charismatic leadership on engagement.

\begin{tabular}{cccc}
\hline & & Engagement & \\
\cline { 2 - 4 } Variable Name & Vigor & Dedication & Absorption \\
\cline { 2 - 4 } & $-0.32^{\star *}$ & $-0.33^{\star *}$ & $-0.53^{\star * *}$ \\
Gender & $0.23^{\star}$ & $0.32^{\star *}$ & $0.27^{\star}$ \\
Age & 0.03 & 0.13 & $0.25^{\star *}$ \\
Education & -0.05 & -0.10 & -0.08 \\
Working Time & 0.04 & 0.04 & 0.01 \\
Working Years & $0.78^{\star * *}$ & $0.73^{\star * *}$ & $0.80^{\star * *}$ \\
Charismatic Leadership & $-0.11^{\star}$ & $-0.11^{\star}$ & -0.06 \\
Authoritarian Leadership & 0.53 & 0.46 & 0.47 \\
$\mathrm{R}^{2}$ & 0.52 & 0.44 & 0.46 \\
$\Delta \mathrm{R}^{2}$ & 52.57 & 39.16 & 40.94 \\
$\mathrm{~F}$ & & &
\end{tabular}

Notes: $\mathrm{N}=335,{ }^{* *} \mathrm{P}<0.001 ;{ }^{* *} \mathrm{P}<0.01 ;{ }^{\star} \mathrm{P}<0.05$. 
Table 5. Summary results of hierarchical regression analysis table.

\begin{tabular}{lllllll}
\hline Vigor & \multicolumn{3}{c}{ Dedication } & \multicolumn{3}{l}{ Absorption } \\
\hline Predictor & Alone & CL\&AL & Alone & CL\&AL & Alone & CL\&AL \\
$\mathrm{CL}$ & $0.79^{* * *}$ & $0.78^{* * *}$ & $0.74^{* * *}$ & $0.73^{* * *}$ & $0.80^{* * *}$ & $0.80^{* * *}$ \\
$\mathrm{~F}(\mathrm{CL})$ & $37.02^{* * *}$ & & $44.55^{* * *}$ & & $52.59^{* * *}$ & \\
$\mathrm{R}^{2}(\mathrm{CL})$ & 0.52 & & 0.45 & & 0.47 & \\
$\Delta \mathrm{R}^{2}(\mathrm{CL})$ & $0.49^{* * *}$ & $0.01^{*}$ & $0.41^{* * *}$ & $0.01^{*}$ & $0.41^{* * *}$ & 0.00 \\
$\mathrm{AL}$ & $-0.17^{* *}$ & $-0.11^{*}$ & $-0.17^{* *}$ & $-0.11^{*}$ & -0.13 & -0.06 \\
$\mathrm{~F}(\mathrm{AL})$ & $8.12^{* *}$ & & $7.39^{* *}$ & & 3.60 & \\
$\mathrm{R}^{2}(\mathrm{AL})$ & 0.05 & & 0.06 & & 0.06 & \\
$\Delta \mathrm{R}^{2}(\mathrm{AL})$ & $0.02^{* *}$ & $0.48^{* * *}$ & $0.02^{* *}$ & $0.40^{* * *}$ & 0.01 & $0.41^{* * *}$ \\
\hline
\end{tabular}

Notes: $\mathrm{N}=335,{ }^{* *} \mathrm{P}<0.001 ;{ }^{* \star} \mathrm{P}<0.01 ;{ }^{\star} \mathrm{P}<0.05$

engagement, so it is assumed that $\mathrm{H} 1 \mathrm{a}, \mathrm{H} 1 \mathrm{~b}$, and $\mathrm{H} 1 \mathrm{c}$ are verified. Authoritarian leadership has a predictive effect on the vigor and dedication dimensions of employee engagement. Therefore, it is assumed that $\mathrm{H} 2 \mathrm{a}$ and $\mathrm{H} 2 \mathrm{~b}$ are verified.

From the results can also be seen in Table 5, when the authoritarian leadership is introduced into the charismatic leadership and engagement relationship model, and the control variables, after excluding the influence of charismatic leadership, authoritarian leaders still have explanatory power for vigor, absorption, $\Delta \mathrm{R}^{2}$ values were $0.01(\mathrm{p}<0.05), 0.01(\mathrm{p}<0.05)$, the dedication does not have additional explanatory power. And in the relationship between authoritarian leadership and employee engagement model introduction of charismatic leadership, and after eliminating the influence of control variables and authoritarian leadership and charismatic leadership still has explanatory power for vigor, dedication and absorption, $\Delta \mathrm{R}^{2}$ value of $0.48(\mathrm{p}<0.001), 0.40(\mathrm{p}<0.001)$, 0.41 ( $\mathrm{p}<0.001)$. By comparison, the charismatic leadership of explanatory power $\left(\Delta R^{2}\right.$ value, vigor of 0.48 , dedication of 0.40$)$ is greater than the authoritarian leadership of explanatory power $\left(\Delta R^{2}\right.$ value, vigor of 0.01 , dedication of 0.01$)$. Absorption on dimensions, charismatic leadership also still have explanatory power $\left(\Delta \mathrm{R}^{2}\right.$ is $\left.0.41, \mathrm{p}<0.001\right)$, but the authoritarian leadership no longer has the explanatory power. Therefore, it can be inferred that charismatic leadership is more effective in predicting engagement than authoritarian leadership, and $\mathrm{H} 3$ has been verified.

\subsection{Analysis of Moderating Effect}

Using engagement as a dependent variable, control variables (age, gender, education, working years, and working time), independent variables (authoritarian leadership and charismatic leadership), moderating variables (task structure), and interactions (authoritarian leadership $\times$ task structure) and (the charismatic leadership $\times$ task structure) respectively enter the regression equation, build Model 1, Model 2 and Model 3 to test the moderating effect of the task structure on the relationship between authoritarian leadership and charismatic leadership 
and employee engagement, the results are shown in Table 6. According to Model 2 , authoritarian leadership $(\beta=-0.09, \mathrm{p}<0.05)$ and charismatic leadership $(\beta$ $=0.77, \mathrm{p}<0.001)$ have a significant impact on employee engagement, and $\mathrm{H} 1$ and $\mathrm{H} 2$ are further supported. It can be seen from Model 3 that the interaction between authoritarian leadership and task structure $(\beta=0.08, \mathrm{p}<0.01)$ has a significant impact on employee engagement, indicating that the task structure significantly moderates the relationship between authoritarian leadership and engagement, H4 It is verified that the interaction influence mode is shown in Figure 2. In the interaction diagram, "high" means one standard deviation above the mean and "low" means one standard deviation below the mean. The interaction between charismatic leadership and task structure has no significant impact on employee engagement, indicating that the task structure has no moderating effect on the relationship between charisma leadership and engagement, and $\mathrm{H} 5$ has not been verified.

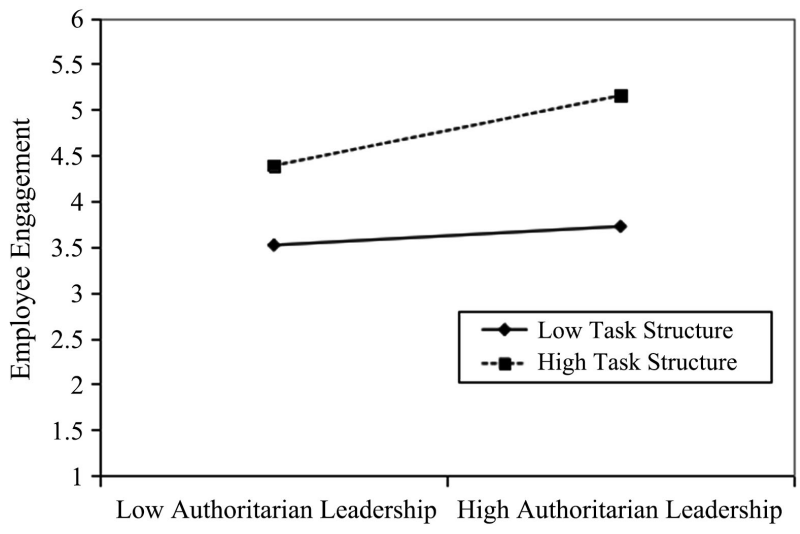

Figure 2. The moderating effect of task structure.

Table 6. Moderating effect analysis results.

\begin{tabular}{cccc}
\hline \multirow{2}{*}{ Variable Name } & \multicolumn{3}{c}{ Engagement } \\
\cline { 2 - 4 } & Model 1 & Model 2 & Model 3 \\
\hline Gender & $-0.42^{* *}$ & $-0.39^{* * *}$ & $-0.41^{* * *}$ \\
Age & 0.01 & $0.27^{*}$ & $0.26^{* *}$ \\
Education & 0.13 & 0.14 & $0.15^{*}$ \\
Working Time & 0.05 & -0.08 & -0.07 \\
Working Years & 0.01 & 0.03 & 0.04 \\
CL & & $0.77^{* * *}$ & $0.72^{* * *}$ \\
AL & & $-0.09^{*}$ & $-0.18^{* * *}$ \\
TS & & & 0.09 \\
CL $\times$ TS & & & 0.05 \\
AL $\times$ TS & & 0.54 & $0.08^{* *}$ \\
$\mathrm{R}^{2}$ & 0.04 & 0.53 & 0.55 \\
$\Delta \mathrm{R}^{2}$ & 0.03 & 55.53 & 0.54 \\
$\mathrm{~F}$ & 2.78 & & 49.16 \\
\hline
\end{tabular}

Notes: $\mathrm{N}=335,{ }^{* *} \mathrm{P}<0.001 ;{ }^{* *} \mathrm{P}<0.01 ;{ }^{\star} \mathrm{P}<0.05$. 
According to the summary, charismatic leadership has a significant positive correlation with employee engagement, and has a significant positive correlation with vigor, dedication and absorption. However, authoritarian leadership has a significant negative correlation with employee engagement, and has a significant negative correlation with vigor and dedication. Charismatic leadership predicts engagement better than authoritarian leadership. Task structure plays a moderating role between authoritarian leadership and employee engagement.

\section{Conclusions}

The empirical results of this study verify some of the hypotheses initially proposed in this paper.

The empirical results show that: 1) Charismatic leadership has a significant positive correlation with employee engagement, and has a significant positive impact on its vigor, absorption and dedication; 2) Authoritarian leadership has a significant negative impact on employee engagement, and has a significant negative impact on the dimension of vigor and dedication, but has no significant impact on the dimension of absorption; 3) Task structure moderates the relationship between authoritarian leadership and employee engagement. The more structured the task, the weaker the negative influence of authoritarian leadership on employee engagement, the less structured the task, and the stronger the negative influence of authoritarian leadership on employee engagement. Task structure has no moderating effect on the relationship between charismatic leadership and employee engagement.

\subsection{Limitations}

Due to limited objective conditions such as time and data collection, there are still some shortcomings in the research, which require further research and discussion. First, this study only analyzes the impact of task structure context factors on the relationship between leader style and subordinate engagement. Secondly, this study is a cross-sectional study. It is more difficult to infer causality. In order to enhance the persuasiveness of causality, longitudinal research design or experimental design should be used in future research to make up for this defect; again, due to situational factors. It is dynamic, multi-faceted, and ambiguous. Therefore, simply using quantitative research methods such as questionnaires does not accurately investigate the degree of impact. Therefore, future research should use qualitative methods such as laboratory and field research to fully investigate the impact of the task structure on the Charismatic leadership style and authoritarian leadership style.

\subsection{Management Advice}

Economic globalization and rapid development of science and technology make the competition between enterprises become increasingly fierce, and the increasingly complex competitive environment puts forward higher requirements for 
employees. In the increasingly fierce enterprise competition, employees' unremitting efforts and active input are the important source of enterprise competitive advantage. This study reveals how to improve employee engagement from the perspective of charismatic leadership.

The organizational culture should encourage charismatic leaders, give more consideration to the needs and expectations of employees, create a fair working atmosphere, and make subordinates take the initiative to improve their engagement.

Organizations can improve the effectiveness of leadership by recognizing authoritarian leadership and charismatic leadership in advance, enhance the positive impact of charismatic leadership on organizations, and reduce the negative impact of authoritarian leadership on organizations. In view of the negative impact of authoritarian leadership, special attention should be paid to the difference between charismatic leadership and authoritarian leadership in the selection, training, promotion and other processes of leadership, so as to establish and improve the training, selection and succession mechanism of leadership talents throughout the organization.

Leaders can adjust their leadership style according to the actual management situation. Managers should take the initiative to understand the differences of subordinate task structure so as to adopt the corresponding leadership style. When dealing with subordinates, leaders should timely change their leadership style according to their different situations. Only in this way can they achieve effective leadership.

\section{Conflicts of Interest}

The authors declare no conflicts of interest regarding the publication of this paper.

\section{References}

[1] Wang, Z., Chen, L. and Li, X. (2015) Transformational Leadership and Work Engagement: An Affect Perspective. Management Review, 9, 120-129.

[2] Harter, J.K., Schmidt, F.L. and Hayes, T.L. (2002) Business-Unit-Level Relationship between Employee Satisfaction, Employee Engagement, and Business Outcomes: A Meta-Analysis. Journal of Applied Psychology, 87, 268-279. https://doi.org/10.1037/0021-9010.87.2.268

[3] Yao, C. and Liu, Y. (2013) Charismatic Leadership and Subordinates' Work Engagement: The Mediation Mechanism of Identification' Two-Dimension Construct. Journal of Psychological Science, 36, 942-948. https://www.psysci.org/CN/Y2013/V36/I4/942

[4] Li, J. and Yang, Z. (2018) The Impact Mechanism of Authoritarian Leadership on Group Voice Climate. Business Management Journal, 6, 53-68.

[5] Farh, J.L. and Cheng, B.S. (2000) A Cultural Analysis of Paternalistic Leadership in Chinese Organizations. Palgrave Macmillan, London, 84-127.

[6] Zheng, B., Zhou, L., Huang, M., et al. (2003) The Ternary Model of Paternalistic Leadership: Evidence from Chinese Mainland Organizations. Native Psychology 
Research, 20, 209-252.

[7] Zhang, X., He, H. and Gu, F. (2009) The Effects of Paternalistic Leading on Team's Achievements: the Mediating Role of Approaches to the Management of Team's Conflicts. Management World, 3, 121-133.

[8] Fiedler, F.E. (1958) Leader Attitudes and Group Effectiveness. University of Illinois Press, Urbana, IL.

https://www.researchgate.net/publication/232569418_Leader_attitudes_and_group_ effectiveness

[9] Yang, J. and Song, H. (2013) The Impact of Task Structure on the Relationship between Vocational Interest and Leadership Performance. Journal of Jiangxi University of Finance \& Economics, 6, 36-43.

[10] Zhang, P., Liu, W. and Liao, J. (2011) The Influence Mechanism of Charismatic Leadership on Employee Creativity: Is Only Psychological Security Enough? Management World, 10, 94-107.

[11] House, R.J. (1977) A 1976 Theory of Charismatic Leadership. In: Hunt, J.G. and Larson, L.L., Eds., Leadership: The Cutting Edge, Southern Illinois University Press, Carbondale, IL, 189-207.

https://www.mendeley.com/catalogue/1976-theory-charismatic-leadership-workingpaper-series-7606/

[12] Bass, B.M. (1985) Leadership and Performance beyond Expectations. Free Press, New York.

[13] Conger, J.A., Kanungo, R.N. and Menon, S.T. (2000) Charismatic Leadership and Follower Effects. Journal of Organizational Behavior, 21, 747-767. https://doi.org/10.1002/1099-1379(200011)21:7<747::AID-JOB46>3.0.CO;2-J

[14] Schaufeli, W.B., Salanova, M., González-Romá, V. and Bakker, A.B. (2002) The Measurement of Engagement and Burnout: A Two Sample Confirmatory Factor Analytic Approach. Journal of Happiness Studies, 3, 71-92. https://doi.org/10.1023/A:1015630930326

[15] Mao, J., Zhou, Z. and Wu, Y. (2017) A Comparative Study of the Relationship Between Transformational Leadership and Authentic Leadership with Teachers' Work Engagement. Teacher Education Research, 29, 48-54.

[16] Howell, J.M. and Shamir, B. (1999) Organizational and Contextual Influences on the Emergence and Effectiveness of Charismatic Leadership. The Leadership Quarterly, 10, 257-283. https://doi.org/10.1016/S1048-9843(99)00014-4

[17] Chen, Y., Jia, L., Li, C., Song, J. and Zhang, J. (2006) Transformational Leadership, Psychological Empowerment and Organizational Commitment of Employees: An Empirical Study in the Chinese Context. Management World, 1, 96-105.

[18] Dong, L., Wu, B. and Huang, W. (2010) Charismatic Leadership, Work Attitude and Group Performance-An Empirical Study in China. Journal of Management, 7, 1484-1489.

[19] Chen, X.P., Eberly, M.B., Chiang, T.J., Farh, J.L. and Cheng, B.S. (2014) Affective Trust in Chinese Leaders: Linking Paternalistic Leadership to Employee Performance. Chinese Journal of Management, 40, 796-819.

https://doi.org/10.1177/0149206311410604

[20] Farh, J.L., Liang, J., Chou, L.F. and Cheng, B.S. (2008) Paternalistic Leadership in Chinese Organizations: Research Progress and Future Research Directions. In: Chen, C.C. and Lee, Y.T., Eds., Leadership and Management in China: Philosophies, Theories and Practices, Cambridge University Press, London, 171-205. 
https://doi.org/10.1017/CBO9780511753763.008

[21] Zhang, A.Y., Tsui, A.S., and Wang, D.X. (2011) Leadership Behaviors and Group Creativity in Chinese Organizations: The Role of Group Processes. The Leadership Quarterly, 22, 851-862. https://doi.org/10.1016/j.leaqua.2011.07.007

[22] Zhang, Y. and Huai, M. (2012) Study on the Relationship between Authoritarian Leadership Behavior and Subordinates' Organizational Citizenship Behavior-The Moderating Role of Subordinates' Power Distance. Management Review, 11, 97-105.

[23] Fu, X. and Li, Y. (2012) The Impact of Paternalistic Leadership on Innovation: An Integrated Model. Nankai Business Review, 2, 121-127.

[24] Li, R. and Tian, X. (2014) Supervisor Authoritarian Leadership and Subordinate Proactive Behavior: Test of A Mediated-Moderation Model. Acta Psychologica Sinica, 11, 1719-1733. https://doi.org/10.3724/SP.J.1041.2014.01719

[25] Erben, G.S. and Guneser, A.B. (2008) The Relationship between Paternalistic Leadership and Organizational Commitment: Investigating the Role of Climate Regarding Ethics. Journal of Business Ethics, 82, 955-968.

https://doi.org/10.1007/s10551-007-9605-z

[26] Fritz, C. and Sonnentag, S. (2009) Antecedents of Day-Level Proactive Behavior: A Look at Job Stressors and Positive Affect during the Workday. Journal of Management, 35, 94-111. https://doi.org/10.1177/0149206307308911

[27] Tang, H., Long, L. and Zhou, R. (2015) Humble Leadership Behavior and Subordinates' Work Engagement: A Mediated Moderation Model. Journal of Management Science, 3, 77-89.

[28] Schaufeli, W.B., Bakker, A.B. and Salanova, M. (2006) The Measurement of Work Engagement with a Short Questionnaire: A Cross-National Study. Educational and Psychological Measurement, 66, 701-716.

https://doi.org/10.1177/0013164405282471 